\title{
Interconnectedness, length and viability of arbuscular mycorrhizal mycelium as affected by selected herbicides and fungicides
}

\author{
Candido Barreto de Novais ${ }^{\mathrm{a}}$, , |Luciano Avio ${ }^{\mathrm{b}}$, Manuela Giovannetti ${ }^{\mathrm{b}}$, Sergio Miana de Faria ${ }^{\mathrm{c}}$, \\ José Oswaldo Siqueira ${ }^{\mathrm{d}}$, Cristiana Sbrana ${ }^{\mathrm{e}}$, \\ ${ }^{a}$ Forestry Institute, Federal Rural University of Rio de Janeiro, Seropédica, Brazil \\ ${ }^{\mathrm{b}}$ Department of Agriculture, Food and Environment, University of Pisa, Italy \\ ${ }^{c}$ Brazilian Agricultural Research Corporation - Embrapa Agrobiologia, Seropédica, Brazil \\ d Department of Soil Science - Sector of Biology, Microbiology and Soil Biological Processes, Federal University of Lavras, Lavras, Brazil \\ ${ }^{\mathrm{e}}$ CNR-Institute of Agricultural Biology and Biotechnology UOS Pisa, Pisa, Italy
}

\section{A R T I C L E IN F O}

Keywords:

Arbuscular mycorrhizal fungi

Mycorrhizal mycelium

Fungicides

Herbicides

Biological soil fertility

Soil bioassay

\begin{abstract}
A B S T R A C T
Arbuscular mycorrhizal fungi (AMF) play a key role in plant nutrition and in the maintenance of soil fertility in agroecosystems, but their survival can be affected by different agricultural practices, including the use of pesticides. In this work, we assessed the impact of chemicals with herbicidal and fungicidal activity on mycelial growth and structure of the worldwide distributed AMF Funneliformis mosseae. Results showed that mycelial growth and interconnectedness of three different $F$. mosseae lineages were affected by the chemicals tested at concentrations lower than those indicated for agricultural use. Indeed, benomyl reduced mycelial growth in one lineage and fenhexamid negatively affected germlings growth in the three lineages, while both fungicides significantly affected mycelial viability and induced abnormal hyphal branching. The three $F$. mosseae lineages showed sensitivity to herbicides, with significant growth and viability decreases in the presence of the active ingredient glufosinate ammonium and a low viability at increasing concentrations of dicamba. Anastomosis rates were reduced by the two fungicides and by very low levels of the herbicide glufosinate, whose impact on AMF networks should be further investigated, given its wide use in agriculture. Our results suggest that the use of some pesticides in agroecosystems may lead to growth reduction and disruption of AMF mycelial structural traits, even in AMF species able to tolerate soil disturbance, posing serious threats to AMF symbiotic performance and to the maintenance of soil mycorrhizal potential.
\end{abstract}

\section{Introduction}

Arbuscular mycorrhizal (AM) fungi (AMF) establish mutualistic symbioses with most crop species and are widespread in agricultural ecosystems all over the world, representing a fundamental element of soil biological fertility (Smith and Read, 2008). AMF are considered key elements for plant nutrition as their hyphae can extend for many meters belowground and absorb and transfer both macro and micro-nutrients from the soil to the colonized roots (Giovannetti et al., 2015). These beneficial fungi are obligate biotrophs, whose life cycle completion depends on their ability to establish symbiotic associations with host roots, through different developmental steps (Sbrana et al., 2017). Spore germination and asymbiotic growth represent critical steps, since they occur in the soil, where the germling mycelium comes into direct contact with all the compounds circulating in the soil solution.

\footnotetext{
* Corresponding author.

Email address: sbrana@ibba.cnr.it (C. Sbrana)
}

Several chemicals are routinely applied in modern agriculture and their residues may persist in soil, raising concerns on their potential impacts on soil microbial activities and community structure. Some non-target microorganisms, among which AMF, show a specific susceptibility towards a number of environmental factors, and hence may be used as bioindicators to evaluate soil quality. Indeed, the reduction or even the disappearance of some AM fungal species, as a consequence of cultural practices characterizing conventional agricultural systems, is an indicator of the decreased stability of the plant-soil system (Helgason et al., 1998; Daniell et al., 2001). Agricultural management involving deep ploughing, chemical fertilization and pesticide use may favour the growth of peculiar AMF taxa, more tolerant to the disruption of extraradical mycelium, environmental stresses and nutritional shifts, thus affecting plant-AMF symbiosis establishment and benefits, AMF community structure and composition and the maintenance of soil mycorrhizal potential (Jansa et al., 2003; Johnson et al., 2003; Na Bhadalung et al., 2005; Castillo et al., 2006; Toljander et al., 2008; Brito et al., 2012). 
Some agricultural chemicals, mainly fungicides, were reported to affect AM fungal activity and symbiosis establishment (Kough et al., 1987; Thingstrup and Rosendahl, 1994; Larsen et al., 1996), with consequent negative impact on host nutrient uptake (Boatman et al., 1978; Hale and Sanders, 1982; Sukarno et al., 1993; Schweiger and Jakobsen, 1998). Tests based on spore germination and asymbiotic hyphal growth have been performed to study the direct effect of pesticides on AMF developmental stages, and showed inhibition of spore germination and germling elongation in Rhizoglomus irregulare, Rhizoglomus intraradices and Funneliformis mosseae grown in the presence of bactericides and fungicides (Venedikian et al., 1999; Giovannetti et al., 2006; Zocco et al., 2008; Calonne et al., 2010; Twanabasu et al., 2013), suggesting that AMF may represent reliable bioindicators for assessing the environmental impact of pollutants and the direct effect of contaminated soils (see ISO 10832: 2009 and Mallmann et al., 2018).

However, AMF showed variable responses when challenged with different chemicals, depending on the experimental systems, the different phases of AM fungal life cycle, the pesticides tested and the taxa involved (Lenoir et al., 2016). The diversity of AM fungal responses has been partly ascribed to the known large genetic variation, potentially affecting not only their symbiotic performances (Siqueira et al., 1991), but also their sensitivity to abiotic stresses (Lenoir et al., 2016). Indeed, some studies supported the hypothesis that genetic variation among AMF modulated their pesticide tolerance and suggested that significant shifts in AM fungal community structure may occur under pesticide stress (Trappe et al., 1984; Schreiner and Bethlenfalvay, 1997; Ipsilantis et al., 2012; Karpouzas et al., 2014)

Hyphal fusions (anastomoses), which regularly occur in asymbiotic and symbiotic mycelium of many AMF, play an important role in the maintenance of nutrient flow and homeostasis within the fungal colony and may represent a mechanism modulating responses to disturbance, thus contributing to fungal fitness and symbiotic performance. As far as we know, only one study investigated the impact of agricultural chemicals on anastomosis ability of the AM fungal isolate Glomus clarum MUCL 46238, reporting a reduction in anastomosis rates in the presence of the fungicide Fenhexamid (Cardenas-Flores et al., 2011).

Here, the impact of different pesticides on AMF during the asymbiotic phase was evaluated on three $F$. mosseae lineages, differing in hyphal growth and anastomosis ability (Sbrana et al., 2018). The aim of the work was to investigate whether their structural and functional traits are affected by the active ingredients contained in herbicides and fungicides. To this aim, we assessed i) mycelium viability and length, ii) occurrence of hyphal morphological alterations/deformations; iii) viability of the abnormal hyphae, iv) rate and density of anastomoses.

\section{Materials and methods}

\subsection{Fungal material}

Pot-cultures of three different lineages of $F$. mosseae (T.H. Nicolson \& Gerd.) C. Walker \& A. Schüßler Yellow Vacuolated isolate (Rothamsted, UK), originating from collections held in Spain (F. mosseae BEG119 from Granada, hereafter GRA, and F. mosseae BEG116 from Barcelona, hereafter BAR) and in Italy (F. mosseae IMA1 from Pisa, hereafter PI) (Sbrana et al., 2018) were maintained for four months in the collection of the Department of Agriculture, Food and Environment, University of Pisa (Italy).

\subsection{Chemicals}

In our experiments, selected agrochemical products (Table 1A) were used at concentrations ranging from a minimum of $1 / 4$ to a maximum of $\times 2$ the recommended field doses $\left(\mathrm{kgha}^{-1}\right)$ of active ingredients for herbaceous plants, which were scaled to the surface of Petri plates utilized for the experiments. Pure active ingredients (Table 1B) were used at concentrations based on results obtained in a previous study (Giovannetti et al., 2006) and in the preliminary experiment. Pure active ingredients (PESTANAL $®$ ) were purchased from Sigma-Aldrich (Milano, Italy).

\subsection{Experimental design}

Experiment 1 had a completely randomized design with five replications and five treatments with different commercial chemicals used in agroecosystems (Table 1A), to test their impact on the growth and anastomosing ability of one $F$. mosseae lineage (PI = IMA1). Experiment 2 had a completely randomized design with five replications and four treatments with selected active ingredients (Table 1B), aimed at evaluating the growth and anastomosing ability of three different $F$. mosseae lineages exposed to such chemicals.

In both experiments, sporocarps were extracted from pot cultures by wet sieving and decanting, flushed into petri dishes and collected with forceps under a dissecting microscope (Wild, Leica, Milano, Italy). Intact, healthy sporocarps were sonicated $(60 \mathrm{~s})$ in a B-1210 cleaner (Branson Ultrasonics, Soest, The Netherlands) and washed three times in sterile distilled water (SDW). For each lineage and chemical treatment concentration, each replicate, consisting of ten sporocarps, was placed in two parallel lines approximately $0.5 \mathrm{~cm}$ apart, on a $47-\mathrm{mm}$-diameter cellulose ester membrane (Millipore ${ }^{\mathrm{TM}}$ HAWP04700, 0.45- $\mu$ m-diameter pores). Each membrane containing 10 paired sporocarps was covered by another empty membrane to complete the sandwich

Table 1

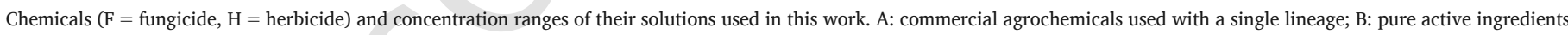
used with three lineages.

\begin{tabular}{|c|c|c|c|c|c|}
\hline \multirow[t]{2}{*}{ A. Agrochemical } & \multicolumn{3}{|l|}{ Active ingredient (a.i.) } & \multirow{2}{*}{$\begin{array}{l}\text { Recommended dose range } \\
\mathrm{gha}^{-1} \text { a.i. }\end{array}$} & \multirow{2}{*}{$\begin{array}{l}\text { Concentration } \\
\mathrm{mgL}^{-1} \text { a.i. }\end{array}$} \\
\hline & & & & & \\
\hline Benlate (Du Pont) (F) & \multicolumn{3}{|c|}{ Benomyl (50) (methyl 1-(butylcarbamoyl)-2-benzimidazolecarbamate) } & $600-800$ & $18.7-300$ \\
\hline Aric $480(\mathrm{SCAM})(\mathrm{H})$ & \multicolumn{3}{|c|}{ Dicamba (40.3) (3,6-dichloro-2-methoxybenzoic acid) } & $100-300$ & $0.6-9.6$ \\
\hline Basta 200 (Bayer) (H) & \multicolumn{3}{|c|}{ Glufosinate ammonium (20) (2-amino-4-(hydroxymethylphosphinyl)butyric acid ammonium salt) } & $500-700$ & $8.8-140$ \\
\hline Disetalin L (BASF) (H) & \multicolumn{3}{|l|}{ Pendimethalin (31.7) } & $500-1300$ & 4.8-76 \\
\hline Teldor (Bayer) (F) & \multicolumn{3}{|c|}{ Fenhexamid (42.8) (N-(2,3-dichloro-4-hydroxyphenyl)-1-methylcyclohexanecarboxamide) } & $500-750$ & $20-320$ \\
\hline \multirow[t]{2}{*}{ B. Active ingredient } & CAS number & Stock solution & Dose range & Control solution & \\
\hline & \multicolumn{5}{|c|}{$\mathrm{mg} \mathrm{L}^{-1}$} \\
\hline Benomyl (F) & $17804-35-2$ & DMSO & $0.1-1.07$ & $0.004 \%$ DMSO in water & \\
\hline Dicamba (H) & 1918-00-9 & Water & $0.45-3.6$ & $100 \%$ water & \\
\hline Fenhexamid (F) & $126833-17-8$ & Ethanol & $10-20$ & $0.02 \%$ ethanol in water & \\
\hline Glufosinate $(\mathrm{H})$ & $77182-82-2$ & Water & $17-70$ & $100 \%$ water & \\
\hline
\end{tabular}


(Giovannetti et al., 1993). In order to establish the chemicals treatments, sandwiches were individually buried in sterile, dried quartz grit in 6-cm-diameter petri dishes and $10 \mathrm{~mL}$ of the relevant solutions were added. Petri dishes were sealed with Parafilm and incubated at $25^{\circ} \mathrm{C}$ in the dark. In experiment 1 , commercial chemicals were diluted with SDW to obtain active ingredients concentrations reported in Table 1A, and a single parallel control was established with SDW. In experiment 2, different controls, with the same diluents used to prepare each active ingredient treatment, were arranged: two controls with SDW for dicamba and glufosinate treatments, a control with dimethyl sulfoxide (DMSO) in SDW for benomyl treatment and a control with ethanol in SDW for fenhexamid treatment (Table 1B).

Membranes containing sporocarps were opened after 30 days incubation and germlings mycelium growing on the membranes was stained for the presence of succinate dehydrogenase activity (SDH), revealed by the deposition of formazan salts in hyphae, which allowed the visualization of viable mycelium and of protoplasmic continuity established between fusing hyphae (Sbrana et al., 2018). In order to assess total mycelial length, the same mycelium was also stained with Trypan blue in lactic acid (0.05\%). Viable and total hyphal length were assessed with the gridline intersect method (Giovannetti and Mosse, 1980) by using a transparent 3-mm-square grid, under a Leica M 205C dissecting microscope (Leica, Milano, Italy). After mounting stained membranes on microscope slides, the number of total and viable deformed hyphal tips, as well as the number of contacts and anastomoses occurring between hyphae were counted on each membrane under a Reichert-Jung Polyvar microscope at magnifications of $\times 125-\times 500$ and verified at a magnification of $\times 1250$. Anastomosis rate was calculated for each replicate membrane by determining the average proportion of hyphal contacts leading to hyphal fusions.

\subsection{Data analysis}

Data of mycelial growth, mycelial viability and morphological alteration number and viability were checked and logarithmically transformed, when needed, to fulfil ANOVA assumptions, and one-way ANOVA, followed by Tukey's HSD multiple range test, or $t$-tests were performed to detect significant differences among pesticide doses, obtained for each lineage. Percentage data were analysed after arcsine transformation.

Regression or correlation analyses were carried out to reveal relationships among all fungal parameters (mycelial growth, mycelial viability, morphological alteration number and viability, anastomosis rate and density) and pesticide doses. All statistical analyses were performed with SPSS Statistics version 23 (IBM Corp., Armon, NY Inc., USA).

\section{Results}

\subsection{Effects of commercial agrochemicals on hyphal length and} anastomosing rates and density of $F$. mosseae

The impact of increasing concentrations, starting from $1 / 4$ of the field dose level, of five different agrochemicals on asymbiotic mycelial growth and anastomosis rate and density of $F$. mosseae PI germlings was evaluated. The results showed differences in hyphal lengths, depending on the concentration and the chemical used (Table 2). The length of mycelium was significantly lower $(P<0.05)$, compared to the control, in the presence of herbicide dosages containing $1.2 \mathrm{mg} \mathrm{L}^{-1}$ or higher of the active ingredient dicamba, $35.2 \mathrm{mg} \mathrm{L}^{-1}$ or higher of glufosinate and $9.6 \mathrm{mg} \mathrm{L}^{-1}$ or higher of pendimethalin (Table 2). Interestingly, treatments with herbicide Aric at dicamba concentration of $0.6 \mathrm{mg} \mathrm{L}^{-1}$ increased germlings hyphal length by $69 \%$.

Anastomosis rates and densities were only affected by the presence of the herbicides Basta and Aric, containing glufosinate and dicamba at concentrations of 70 and $4.8 \mathrm{mg} \mathrm{L}^{-1}$, respectively. Germlings grown in these treatments showed significantly lower (Basta) and higher (Aric) values for anastomosis rates and densities, compared with the control (Fig. 1). No impact on mycelial interconnectedness was detected in germlings exposed to all the other chemical treatments.

As Benlate completely inhibited spore germination even at the lowest concentration and Teldor allowed erratic germination and limited hyphal growth only at $20 \mathrm{mg} \mathrm{L}^{-1}$ concentration of the active ingredient fenhexamid, it was not possible to obtain data for such fungicides.

\subsection{Impact of four active ingredients on mycelial growth, viability and morphological traits of $F$. mosseae germlings}

Results reported in Section 3.1 allowed the selection of two herbicidal active ingredients (dicamba and glufosinate) and suggested that the two fungicides (benomyl and fenhexamid) had to be tested at lower concentration ranges: tests carried out with such active ingredients showed that the three lineages of $F$. mosseae responded differently to the chemicals tested, with significant variation in mycelial growth and viability, depending on chemicals and concentration levels (Table 3).

The growth of lineages BAR and GRA was not affected by any tested concentration of benomyl and dicamba, while that of PI showed a growth reduction response to both chemicals. Indeed, PI showed high sensitivity to benomyl, as $1 \mathrm{mg} \mathrm{L}^{-1}$ drastically reduced mycelial growth, up to $-66 \%$ compared with the control (Table 3 ). In the presence of dicamba, PI growth response confirmed that observed when using the herbicide Aric (Section 3.1), since $0.45 \mathrm{mg} \mathrm{L}^{-1}$ dicamba concentration increased PI germlings hyphal growth by $55 \%$, whereas $0.9 \mathrm{mg} \mathrm{L}^{-1}$ concentration produced $70 \%$ growth reduction, compared with controls (Table 3).

The three different lineages of $F$. mosseae showed a dose-effect response to glufosinate and fenhexamid, with significant mycelial growth

Table 2

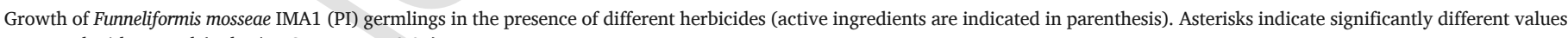
compared with control (Tukey's HSD test, $P<0.05$ ).

\begin{tabular}{|c|c|c|c|c|c|c|c|}
\hline Level & Aric 480 (dicamba) & Hyphal growth & Basta 200 (glufosinate) & Hyphal growth & Disetalin L (pendimethalin) & Hyphal growth & Hyphal growth in SDW ${ }^{\mathrm{a}}$ \\
\hline & $\mathrm{mgL}^{-1}$ & $\mathrm{~mm}$ & $\mathrm{mgL}^{-1}$ & $\mathrm{~mm}$ & $\mathrm{mgL}^{-1}$ & $\mathrm{~mm}$ & $\mathrm{~mm}$ \\
\hline 0 & & & & & & & $767.3 \pm 34.7^{\mathrm{b}}$ \\
\hline 1 & 0.6 & $1296.3 \pm 109.1^{*}$ & 8.8 & $380.6 \pm 99.4$ & 4.8 & $936.9 \pm 13.3$ & \\
\hline 2 & 1.2 & $186.8 \pm 27.6^{*}$ & 17.6 & $582.4 \pm 27.6$ & 9.6 & $326.2 \pm 71.8^{*}$ & \\
\hline 3 & 2.4 & $231.6 \pm 15.5^{*}$ & 35.2 & $162.2 \pm 15.5^{*}$ & 19.2 & $197.8 \pm 45.3^{*}$ & \\
\hline 4 & 4.8 & $238.1 \pm 31.1^{*}$ & 70 & $137.6 \pm 31.1^{*}$ & 38 & $270.9 \pm 19.6^{*}$ & \\
\hline 5 & 9.6 & $582.4 \pm 87.5^{*}$ & 140 & $252.2 \pm 84.8^{*}$ & 76 & $172.3 \pm 5.7^{*}$ & \\
\hline
\end{tabular}

a $\mathrm{SDW}=$ sterile distilled water.

b A single control trial was established for all treatments. 
a)

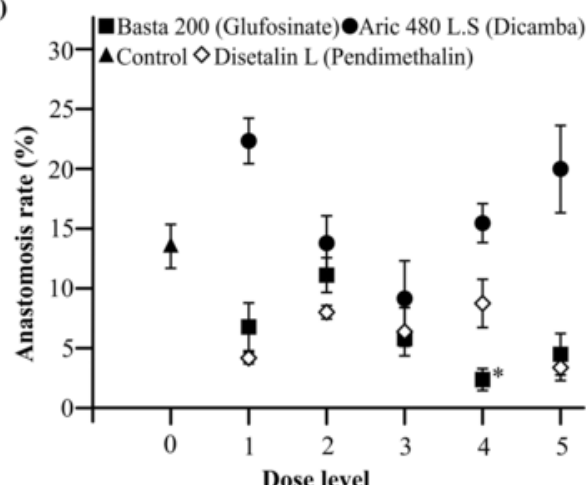

b)

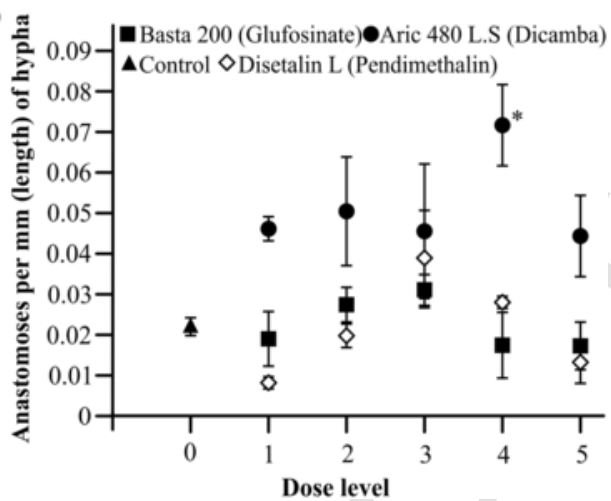

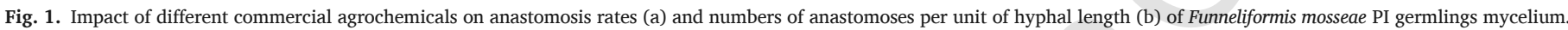

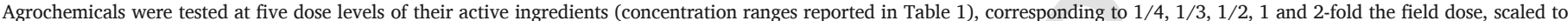
the surface of the Petri plate. Asterisks indicate significantly different values compared with controls $(P<0.05)$.

Table 3

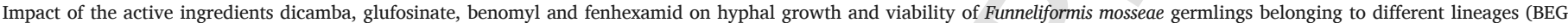
$119=$ GRA, BEG $116=$ BAR and IMA1 = PI).

\begin{tabular}{|c|c|c|c|c|c|c|}
\hline \multirow[t]{2}{*}{ Active ingredient } & \multicolumn{3}{|c|}{ Hyphal length per germinated sporocarp } & \multicolumn{3}{|c|}{ Mycelium viability } \\
\hline & GRA & BAR & PI & GRA & BAR & PI \\
\hline $\operatorname{mgL}^{-1}$ & $\mathrm{~mm}$ & & & $\%$ & & \\
\hline \multicolumn{7}{|l|}{ Dicamba } \\
\hline 0 & $40.5 \pm 7.1$ & $194.7 \pm 20.3$ & $69.7 \pm 3.1 \mathrm{a}^{\dagger}$ & $98 \pm 0.6 \mathrm{a}$ & $95 \pm 0.9 \mathrm{a}$ & $98 \pm 0.9 \mathrm{a}$ \\
\hline 0.45 & $46.9 \pm 4.9$ & $185.1 \pm 25.0$ & $108.0 \pm 9.1 \mathrm{a}$ & $96 \pm 0.9 a$ & $95 \pm 0.6 \mathrm{a}$ & $98 \pm 1.2 \mathrm{a}$ \\
\hline 0.90 & $41.4 \pm 7.7$ & $218.0 \pm 26.1$ & $20.7 \pm 3.1 \mathrm{~b}$ & $96 \pm 0.9 \mathrm{a}$ & $93 \pm 0.9 \mathrm{a}$ & $76 \pm 0.9 b$ \\
\hline 1.81 & $41.1 \pm 18.3$ & $191.8 \pm 25.0$ & $21.0 \pm 1.4 \mathrm{~b}$ & $81 \pm 0.6 \mathrm{~b}$ & $80 \pm 0.9 \mathrm{~b}$ & $73 \pm 1.2 \mathrm{~b}$ \\
\hline 3.62 & $70.4 \pm 11.5$ & $156.4 \pm 23.1$ & $26.4 \pm 3.5 b$ & $80 \pm 0.9 b$ & $78 \pm 0.9 \mathrm{~b}$ & $75 \pm 1.2 \mathrm{~b}$ \\
\hline One-way ANOVA & $\begin{array}{l}\mathrm{F}_{4,20}=1.3 \\
P=0.29\end{array}$ & $\begin{array}{l}\mathrm{F}_{4,20}=0.8 \\
P=0.51\end{array}$ & $\begin{array}{l}\mathrm{F}_{4,20}=44.4 \\
P<0.001\end{array}$ & $\begin{array}{l}\mathrm{F}_{4,20}=134.9 \\
P<0.001\end{array}$ & $\begin{array}{l}\mathrm{F}_{4,20}=111.5 \\
P<0.001\end{array}$ & $\begin{array}{l}\mathrm{F}_{4,20}=138.4 \\
P<0.001\end{array}$ \\
\hline \multicolumn{7}{|l|}{ Glufosinate } \\
\hline 0 & $99.4 \pm 1.4 \mathrm{a}$ & $99.3 \pm 6.2 \mathrm{a}$ & $91.2 \pm 12.1 \mathrm{a}$ & $99 \pm 0.3 \mathrm{a}$ & $98 \pm 0.6 \mathrm{a}$ & $99 \pm 0.6 \mathrm{a}$ \\
\hline 17 & $48.8 \pm 5.4 b$ & $42.8 \pm 8.1 b$ & $59.7 \pm 5.2 \mathrm{ab}$ & $92 \pm 0.6 b$ & $94 \pm 0.6 b$ & $97 \pm 0.6 \mathrm{ab}$ \\
\hline 35 & $18.9 \pm 8.2 c$ & $44.8 \pm 3.7 b$ & $38.8 \pm 9.5 \mathrm{~b}$ & $82 \pm 0.6 c$ & $95 \pm 0.7 \mathrm{ab}$ & $96 \pm 0.6 \mathrm{ab}$ \\
\hline 70 & $11.6 \pm 3.3 c$ & $24.7 \pm 5.6 b$ & $40.5 \pm 5.6 b$ & $82 \pm 0.6 c$ & $95 \pm 0.6 \mathrm{~b}$ & $95 \pm 1.2 \mathrm{~b}$ \\
\hline One-way ANOVA & $\begin{array}{l}\mathrm{F}_{3,16}=58.3 \\
P<0.001\end{array}$ & $\begin{array}{l}\mathrm{F}_{3,16}=27.9 \\
P<0.001\end{array}$ & $\begin{array}{l}\mathrm{F}_{3,16}=8.1 \\
P=0.002\end{array}$ & $\begin{array}{l}\mathrm{F}_{3,16}=249.7 \\
P<0.001\end{array}$ & $\begin{array}{l}\mathrm{F}_{3,16}=8.1 \\
P=0.008\end{array}$ & $\begin{array}{l}\mathrm{F}_{3,16}=5.0 \\
P=0.03\end{array}$ \\
\hline \multicolumn{7}{|l|}{ Benomyl } \\
\hline 0 & $57.9 \pm 10.2$ & $68.2 \pm 13.5$ & $81.3 \pm 4.7 \mathrm{a}$ & $99 \pm 0.6 \mathrm{a}$ & $97 \pm 0.9 \mathrm{a}$ & $94 \pm 0.6 \mathrm{a}$ \\
\hline 0.107 & $54.4 \pm 6.1$ & $55.0 \pm 8.3$ & $46.5 \pm 4.1 \mathrm{~b}$ & $94 \pm 0.6 b$ & $92 \pm 1.2 \mathrm{a}$ & $91 \pm 0.6 \mathrm{a}$ \\
\hline 1.07 & $40.2 \pm 4.1$ & $60.4 \pm 13.7$ & $27.3 \pm 4.0 \mathrm{c}$ & $93 \pm 0.6 b$ & $92 \pm 1.2 \mathrm{a}$ & $73 \pm 0.9 b$ \\
\hline One-way ANOVA & $\begin{array}{l}\mathrm{F}_{2,12}=1.7 \\
P=0.23\end{array}$ & $\begin{array}{l}\mathrm{F}_{2,12}=0.3 \\
P=0.75\end{array}$ & $\begin{array}{l}\mathrm{F}_{2,12}=40.4 \\
P<0.001\end{array}$ & $\begin{array}{l}\mathrm{F}_{2,12}=31.0 \\
P<0.001\end{array}$ & $\begin{array}{l}\mathrm{F}_{2,12}=5.7 \\
P=0.04\end{array}$ & $\begin{array}{l}\mathrm{F}_{2,12}=259.0 \\
P<0.001\end{array}$ \\
\hline \multicolumn{7}{|l|}{ Fenhexamid } \\
\hline 0 & $111.8 \pm 14.4 \mathrm{a}$ & $151.8 \pm 18.8 \mathrm{a}$ & $146.7 \pm 29.0$ & $97 \pm 0.7 \mathrm{a}$ & $97 \pm 0.9 \mathrm{a}$ & $99 \pm 0.6 \mathrm{a}$ \\
\hline 10 & $78.5 \pm 14.9 \mathrm{ab}$ & $50.0 \pm 1.1 \mathrm{~b}$ & $90.9 \pm 6.0$ & $82 \pm 0.9 \mathrm{~b}$ & $88 \pm 0.9 b$ & $76 \pm 1.2 \mathrm{~b}$ \\
\hline 20 & $38.8 \pm 5.0 \mathrm{~b}$ & $35.8 \pm 6.5 b$ & $79.4 \pm 11.2$ & $81 \pm 0.9 b$ & $86 \pm 1.2 \mathrm{~b}$ & $74 \pm 1.2 b$ \\
\hline One-way ANOVA & $\begin{array}{l}\mathrm{F}_{2,12}=8.8 \\
P=0.004\end{array}$ & $\begin{array}{l}\mathrm{F}_{2,12}=31.0 \\
P<0.001\end{array}$ & $\begin{array}{l}\mathrm{F}_{2,12}=3.9 \\
P=0.05\end{array}$ & $\begin{array}{l}\mathrm{F}_{2,12}=131.7 \\
P<0.001\end{array}$ & $\begin{array}{l}\mathrm{F}_{2,12}=32.6 \\
P=0.001\end{array}$ & $\begin{array}{l}\mathrm{F}_{2,12}=183.9 \\
P<0.001\end{array}$ \\
\hline
\end{tabular}

$\dagger$ In columns, and for each active ingredient, means ( \pm standard error of mean) followed by the same letter do not differ significantly at $P<0.05$ by Tukey's HSD test.

reduction even at minimal concentrations (Table 3). Regression analyses showed a negative linear relationship between glufosinate concentrations and hyphal growth of the three $\mathrm{AMF}\left(\mathrm{R}^{2}=0.83,0.81\right.$ and 0.50 ; $P<0.001$ for GRA, BAR and PI, respectively). In the presence of the highest glufosinate concentration tested the length of GRA mycelium was $88 \%$ lower than that detected in the control treatment. At such concentration, mycelial growth of BAR and PI were reduced by 75 and $55 \%$, respectively, compared with controls (Table 3).

Mycelial viability showed consistent reductions, compared with controls, when germlings belonging to the three lineages were challenged with all the different chemicals, with the exception of BAR in the presence of benomyl (Table 3). Significant regression was detected for all $F$. mosseae lineages tested when analyzing viability values obtained from dicamba $\left(\mathrm{R}^{2}=0.79,0.82\right.$ and $0.54 ; P=0.001,0.001,0.002$ for GRA, BAR and PI, respectively) and fenhexamid $\left(\mathrm{R}^{2}=0.80,0.83\right.$ and $0.81 ; P=0.001,0.001,0.001$ for GRA, BAR and PI, respec- tively) experiments. On the contrary, only GRA and PI showed significant reduction in viability in the presence of glufosinate $\left(\mathrm{R}^{2}=0.66\right.$ and 0.53; $P=0.001$ and 0.008 , respectively) and benomyl $\left(\mathrm{R}^{2}=0.44\right.$ and $0.99 ; P=0.05$ and 0.001 , respectively).

In samples of germlings grown in the presence of glufosinate, even at the lowest concentration level tested, morphological alterations were detected in hyphae, characterized by living incipient lateral branch protrusions (Fig. 2a) and by short lateral branches where protoplasm was often retracted forming septa separating living from dead hyphal compartments (Fig. 2b). The number of short lateral branches increased, and their viability decreased, with increasing glufosinate concentrations (Table 4), while lateral branch protrusion numbers were not related with the herbicide doses. In the presence of the highest concentration level of fenhexamid and of both tested concentrations of Benomyl, multiple deformed hyphal tips were produced, frequently in the apical region of hyphae (Fig. 2c-e). Interestingly, such deformed 


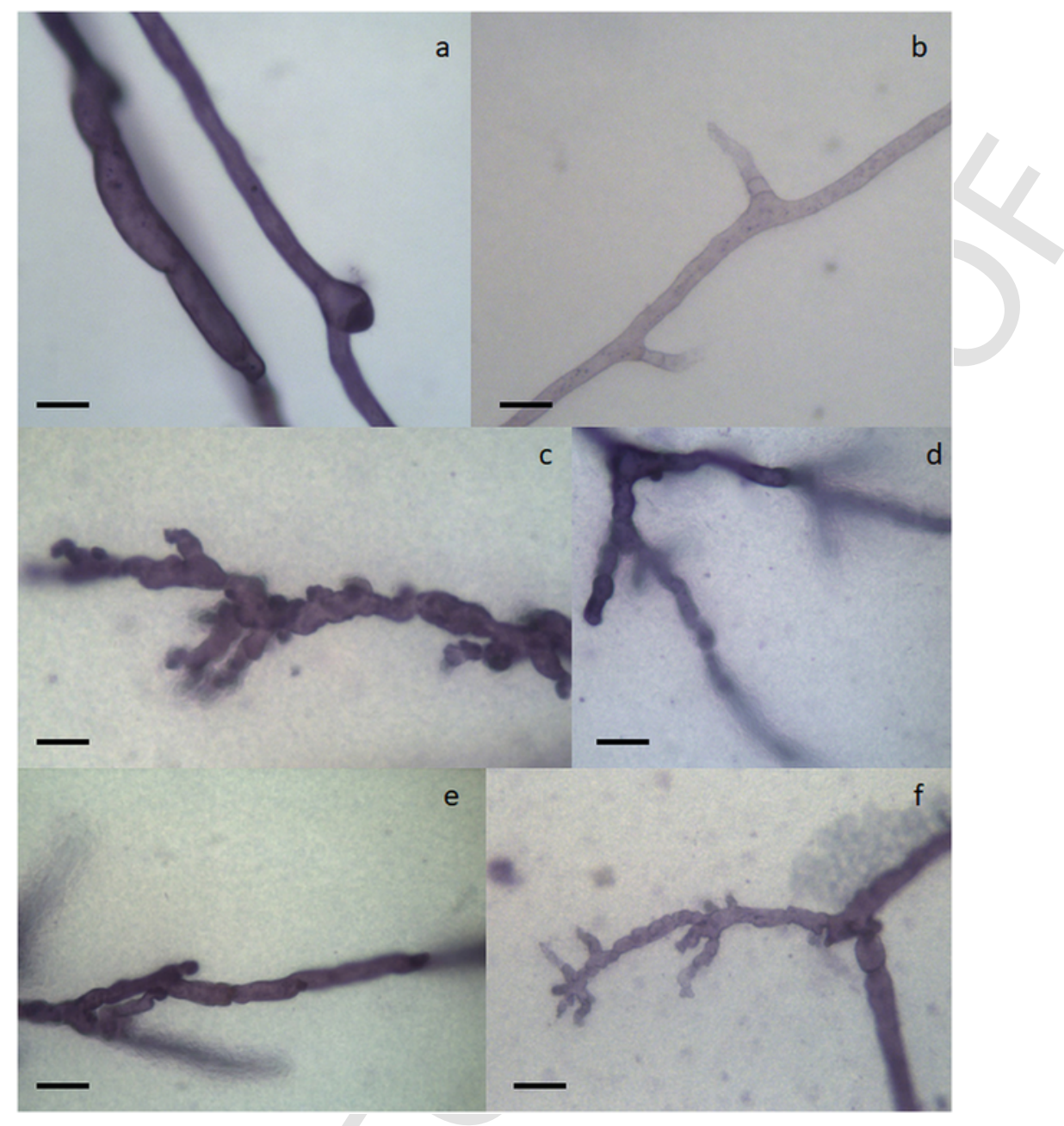

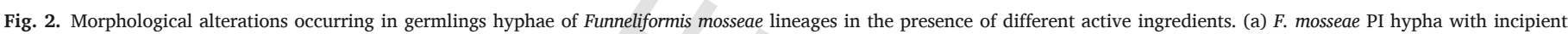

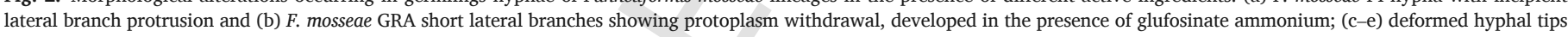

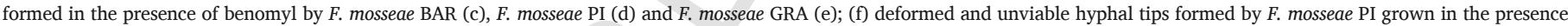
of fenhexamid. Scale bars $=12 \mu \mathrm{m}$.

tips appeared viable in germlings grown in the presence of benomyl, although not all of them were detected, due to their ability to grow into the membrane (Fig. 2c-e), while about $50 \%$ of tips were dead in germlings challenged with fenhexamid (Table 4, Fig. 2f).

\subsection{Impact of four active ingredients on anastomosis rates and density of F. mosseae germlings}

The impact of chemicals on anastomosis rates varied depending on the AMF lineage and identity, and on the concentration of the chemical compound tested (Fig. 3). dicamba did not show effects on the anastomosis rate of the three different lineages (Fig. 3a), whereas glufosinate reduced anastomosis rates, showing a negative correlation with its concentration, independently on the lineage (Pearson's $r=-0.53$, $P<0.001$; Fig. 3e). benomyl and fenhexamid exerted a considerable inhibitory action on GRA anastomosis rate (Fig. 3c and g), which was significantly lower $(-73 \%)$ than the control in the presence of $1.07 \mathrm{mg} \mathrm{L}^{-1}$ of benomyl (One way ANOVA $\mathrm{F}_{2,12}=7.9, P=0.006$ ).

The number of anastomoses per $\mathrm{mm}$ of hypha (anastomosis density) formed by GRA and BAR, ranging from $0.06 \pm 0.007$ to $0.11 \pm 0.02$ and $0.09 \pm 0.01$ to $0.14 \pm 0.01$, respectively, did not differ from controls, even at the highest concentrations of dicamba, whereas anastomosis density of PI increased with dicamba concentration, showing significantly higher values at the highest dose, compared with controls (One way ANOVA $\mathrm{F}_{4,20}=2.9, P=0.05$; Fig. $3 \mathrm{~b}$ ). Benomyl and glufosi- nate did not show any effect on the density of anastomoses formed by BAR and PI, while values obtained for GRA were reduced by increasing concentrations of these chemicals: values obtained at the highest doses of benomyl were significantly lower compared with control (One way ANOVA $\mathrm{F}_{2,12}=5.4, P=0.02$; Fig. $3 \mathrm{~d}$ and f). No impact of increasing fenhexamid concentrations was observed on anastomosis density, with the exception of the lineage BAR, where the reduction of hyphal growth caused a significant increase of such values (One way ANOVA $\mathrm{F}_{2,12}=9.7, P=0.003$; Fig. 3h).

\section{Discussion}

In this work, the majority of herbicides and fungicides doses tested showed negative impact on asymbiotic growth and anastomosis ability of three AMF lineages belonging to the species $F$. mosseae. This finding is particularly important, as this species has a global distribution and tolerates a wide range of environmental conditions, including frequent soil disturbance and fungicides use (Öpik et al., 2006; Sýkorová et al., 2007; Ipsilantis et al., 2012).

The experimental model system allowed the assessment of the impact of chemical products used in agriculture on spore germination, asymbiotic mycelial growth and anastomosis formation of AMF germlings. Such and similar bioassays may be utilized to test agricultural chemicals also on ERM, either in whole plant systems in vivo or in monoxenic cultures in vitro, although not all AMF species are able to 
Table 4

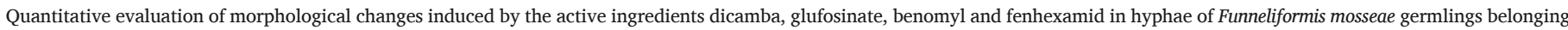
to different lineages (BEG $119=$ GRA, BEG $116=$ BAR and PI).

\begin{tabular}{|c|c|c|c|c|c|c|}
\hline \multirow[t]{2}{*}{ Active ingredient } & \multicolumn{3}{|c|}{ Short lateral hyphal tips } & \multicolumn{3}{|c|}{ Short lateral hyphal tips viability } \\
\hline & GRA & BAR & PI & GRA & BAR & PI \\
\hline $\mathrm{mgL}^{-1}$ & \multicolumn{2}{|c|}{ number mm hypha ${ }^{-1}$} & & \multicolumn{2}{|l|}{$\%$} & \\
\hline \multicolumn{7}{|l|}{ Glufosinate } \\
\hline 0 & 0 & 0 & 0 & & & \\
\hline 17 & $0.06 \pm 0.01$ & $0.03 \pm 0.01$ & $0.04 \pm 0.01$ & $12.9 \pm 5.0$ & $33.3 \pm 3.0$ & $17.6 \pm 2.4$ \\
\hline 35 & $0.3 \pm 0.16$ & $0.06 \pm 0.01$ & $0.09 \pm 0.02$ & $8.7 \pm 2.0$ & $13.7 \pm 4.3$ & $11.6 \pm 2.3$ \\
\hline 70 & $0.33 \pm 0.04$ & $0.11 \pm 0.01$ & $0.14 \pm 0.05$ & $8.8 \pm 0.1$ & $10.0 \pm 0.6$ & $8.6 \pm 1.0$ \\
\hline \multirow[t]{2}{*}{$\mathrm{R}^{2 \mathrm{a}}$} & 0.76 & 0.76 & 0.65 & 0.09 & 0.60 & 0.55 \\
\hline & $P<0.001$ & $P<0.001$ & $P=0.002$ & $P=0.425$ & $P=0.014$ & $P=0.022$ \\
\hline Active ingredient & \multicolumn{3}{|c|}{ Deformed hyphal tips } & \multicolumn{2}{|c|}{ Deformed hyphal tips viability } & \\
\hline & GRA & BAR & PI & GRA & BAR & PI \\
\hline $\mathrm{mgL}^{-1}$ & \multicolumn{3}{|c|}{ number mm hypha ${ }^{-1}$} & $\%$ & & \\
\hline \multicolumn{7}{|l|}{ Fenhexamid } \\
\hline 0 & 0 & 0 & 0 & & & \\
\hline 10 & 0 & 0 & 0 & & & \\
\hline 20 & $0.11 \pm 0.02 *$ & $0.16 \pm 0.05^{*}$ & $0.02 \pm 0.001$ & $44.4 \pm 6.8$ & $51.2 \pm 10.2$ & $53.8 \pm 3.9$ \\
\hline \multicolumn{7}{|l|}{ Benomyl } \\
\hline 0 & 0 & 0 & 0 & & & \\
\hline 0.107 & $0.003 \pm 0.001$ & $0.004 \pm 0.002$ & $0.017 \pm 0.002$ & 100 & 100 & 100 \\
\hline 1.07 & $0.03 \pm 0.008^{*}$ & $0.028 \pm 0.006^{*}$ & $0.064 \pm 0.010^{*}$ & 100 & 100 & 100 \\
\hline
\end{tabular}

a For glufosinate, statistical results of linear regressions are reported.

* For fenhexamid and benomyl, asterisks indicate significantly different values compared with control $(t$-test, $P<0.05)$.

grow in vitro (Declerck and Strullu, 2005). However, it is important to note that in symbiotic systems it is difficult to distinguish between direct effects on AMF mycelium and the indirect effects caused by alterations induced by pesticides in host plant physiology, which may affect fungal symbionts (Campagnac et al., 2008; Calonne et al., 2012).

Here, differential responses to the presence of chemicals were observed among the three $F$. mosseae lineages, which previously showed genetic and phenotypic divergence (Sbrana et al., 2018). Present results suggest that genetic variations regulating AMF sensitivity to stress do not only occur at species and isolate levels, but also within the same isolate, possibly due to genetic exchange and segregation acting upstream offspring production (Angelard et al., 2010; Ehinger et al., 2012).

The AMF F. mosseae isolate PI was negatively influenced by most of the products tested in Experiment 1, and its spore germination and growth were inhibited by fungicides containing benomyl and fenhexamid, even at doses below the recommended field rate. This is consistent with previous studies carried out in vitro (Chiocchio et al., 2000), reporting that spore germination rates of $F$. mosseae were significantly reduced at $1 \mathrm{mg} \mathrm{L}^{-1}$ and completely inhibited at $10 \mathrm{mg} \mathrm{L}^{-1}$ of benomyl.

Our results also showed that doses below $1.07 \mathrm{mg} \mathrm{L}^{-1}$ of benomyl and $20 \mathrm{mgL}^{-1}$ of fenhexamid had no inhibitory effect on $F$. mosseae spore germination, although differential sensitivity of growing germlings to these fungicides was detected among the three different lineages. In our experimental conditions, even $0.1 \mathrm{mg} \mathrm{L}^{-1}$ of benomyl reduced PI mycelial growth, while lineages BAR and GRA presented a higher degree of intrinsic tolerance. On the contrary, $10 \mathrm{mgL}^{-1}$ fenhexamid affected germlings growth in all the lineages, reducing hyphal lengths up to $-67.1 \%$ (lineage BAR). Both fungicides also significantly affected mycelial viability, with the exception of benomyl on lineage BAR. benomyl, which is converted to carbendazim in soil, is known to inhibit the organization of microtubules (Hammersachlag and Sisler, 1973; Richmond and Phillips, 1975; Howard and Aist, 1980; Davidse, 1986), thus affecting mycelial growth. In an early work, it was reported that $0,01 \mathrm{mg} \mathrm{L}^{-1}$ of Benomyl and lower concentrations of carbendazim were able to inhibit spore germination and hyphal growth of $F$. caledonius and F. mosseae (Carr and Hinkley, 1985; Venedikian et al.,
1999). The negative impact of this fungicide on AMF was reported in several studies, which detected reductions in P uptake and hyphal transport from soil to plants (Hale and Sanders, 1982; Sukarno et al., 1993; Larsen et al., 1996; Kling and Jakobsen, 1997), in mycorrhizal colonization (Boatman et al., 1978), in intraradical hyphal enzymatic activity (Kough et al., 1987; Thingstrup and Rosendahl, 1994) and in growth and activity of external hyphae (Sukarno et al., 1993). Fenhexamid (hydroxyanilide) acts by inhibiting the 3-ketoreductase (Debieu et al., 2001), one of the components of the enzymatic complex involved in C-4 demethylation during the ergosterol biosynthesis. Previous studies on sterol biosynthesis in AMF suggested that these compounds play an essential role in the maintenance of membrane integrity and functioning and in cell wall synthesis (Fontaine et al., 2001; Campagnac et al., 2008). The negative effects of fenhexamid previously recorded on AMF spore germination rates and on growth, architecture and physiology of extraradical mycelium are consistent with our data (Dodd and Jeffries, 1989; Zocco et al., 2008, 2011).

The F. mosseae lineage PI was sensitive to herbicides, and pendimethalin showed a lower growth inhibitory dose compared with Basta, confirming previous works on the impact of these and other herbicides on AMF spore germination and growth in the same experimental system (Giovannetti et al., 2006). Interestingly, the herbicide pendimethalin, when applied via soil, was also able to reduce AMF colonization in corn (Zea mays) plants (Siqueira et al., 1991). A shared sensitivity to herbicides was also detected in growing germlings of the three $F$. mosseae lineages, which showed significant growth and viability decreases in the presence of the active ingredient glufosinate and reduced viability at increasing concentrations of dicamba, although with this compound mycelial growth decreased only in lineage PI. The non-selective herbicide glufosinate ammonium is a structural analogue of glutamate and inhibits the activity of glutamine synthetase by irreversible binding, leading to ammonia and free radicals accumulations and cell starving in plants and microorganisms. Compared with the more studied herbicide glyphosate, glufosinate ammonium appears to have a greater impact on microbial communities, even at low dosages (Rose et al., 2016). In a previous study with the same experimental system, germination rates of the AMF tested were lower in the presence of 
a)
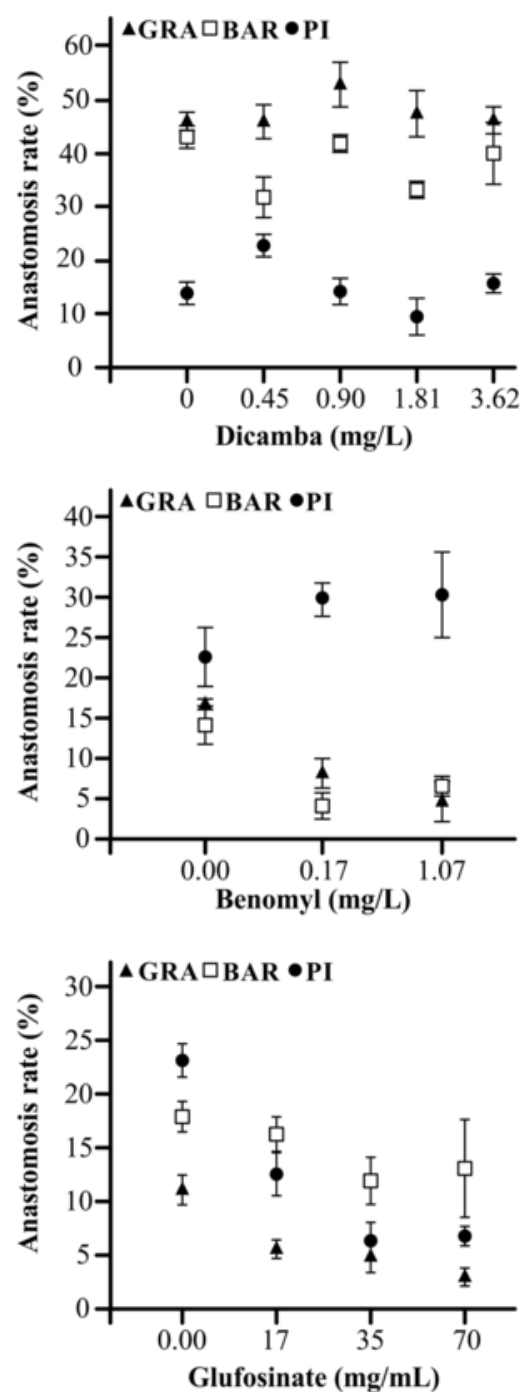

g)

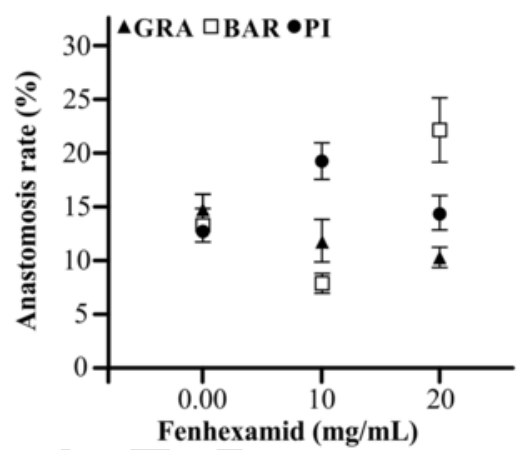

b)

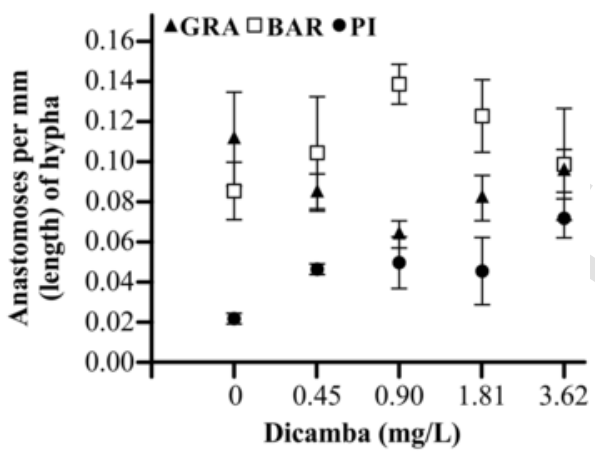

d)

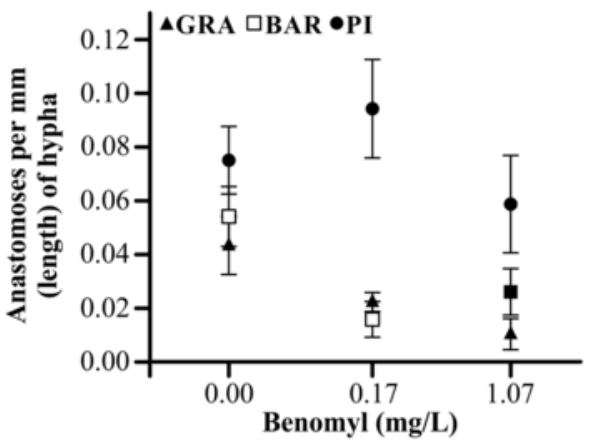

f)

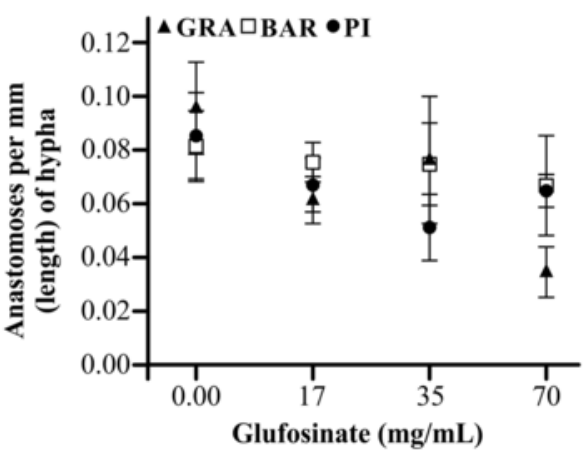

h)

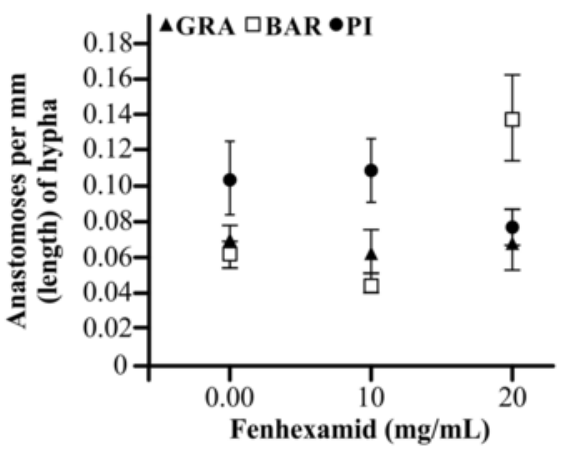

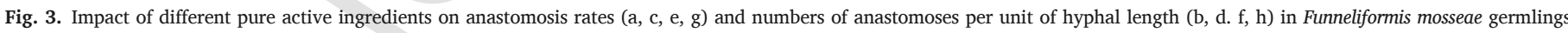
belonging to different lineages (GRA, BAR and PI).

glufosinate than in controls, although a dose-effect relationship was not detected (Giovannetti et al., 2006). Our results are consistent with other works showing that sublethal doses of glufosinate were able to reduce fungal growth in Trichoderma (Ahmad et al., 1995), Plasmopara viticola (Kortekamp, 2008), Guignardia bidwellii and Penicillium expansum (Albrecht and Kortekamp, 2009), Rhizoctonia solani (Uchimiya et al., 1993) and Aspergillus flavus (Tubajika and Damann Jr, 2002). Moreover, glufosinate ammonium reduced hyphal growth and hindered appressoria formation by Magnaporthe grisea and Cochliobolus miyabeanus (Ahn, 2008). Dicamba and other synthetic auxin herbicides mimic IAA effects and, when present at high concentrations in tissues, elicit distorted cell division and expansion, resulting in systemic plant structural alteration. Inhibitory activity of dicamba on fungal growth was reported for Nigrospora oryzae and Nigrospora sphaerica in vitro (Abass, 2017) and for Rhizoctonia cerealis in vivo (Gisi, 1996), while other hormonal herbicides like MCPA exerted a reduction of AMF root colonization (Garcia-Romera and Ocampo, 1988). Interestingly, fungitoxicity of dicamba on PI mycelial growth was dependent on the concentration tested, since at low concentrations (i.e. $0.45 \mathrm{mg} \mathrm{L}^{-1}$ ) mycelial growth increased by $69 \%$ compared with control and high viability was main- 
tained, while at concentrations of $0.9 \mathrm{mgL}^{-1}$, and higher, a dramatic growth and viability reduction was observed. Such phenomenon resembles the stimulation of hyphal elongation observed in AMF germling hyphae at high concentrations of heavy metals (Bartolome-Esteban and Schenck, 1994; Pawlowska and Charvat, 2004) and in other fungi exposed to toxic compounds (Fomina et al., 2003) and may represent a fungal strategy to escape local contaminated patches. Indeed, in vitro germlings of Rhizophagus clarus exposed to Fenhexamid showed straight hyphal morphology, while control hyphae appeared undulated (Cardenas-Flores et al., 2011).

In this work, the two fungicides differentially influenced the ability of $F$. mosseae lineages to perform hyphal fusions: anastomosis rates of lineage GRA were negatively affected by both compounds, while those of BAR were reduced by benomyl only and PI frequencies were not affected. Moreover, the anastomosis density (per hyphal unit length) of germlings mycelium was reduced in GRA and BAR grown in the presence of benomyl and not affected in all the other treatments. In a previous work, a reduction in anastomosis rate was observed in $R$. clarus at concentration of $10 \mathrm{mgL}^{-1}$ Fenhexamid (Cardenas-Flores et al., 2011). However, the fungicides tested appeared not to disrupt the germlings network, which maintained its interconnectedness and viability. This may be due to an AMF adaptation mechanism, aimed at maintaining membrane functionality under fungicide stress, as suggested by increases in the content of some unsaturated fatty acids and phosphatidylcholine observed in $R$. irregulare grown in the presence of another sterol biosynthesis inhibitor, the fungicide propiconazole (Calonne et al., 2010).

Anastomosis rates were not affected in germlings of the three $F$. mosseae lineages exposed to the different dicamba concentrations, while they were significantly reduced in all lineages grown in the presence of glufosinate doses higher than $0.035 \mathrm{mg} \mathrm{L}^{-1}$. As far as we know, no information on fungal anastomosing behaviour in the presence of herbicides has been previously reported, thus the observed glufosinate impact on AMF networks should be deeper investigated, due to the wide use in agriculture of such highly effective herbicide.

Here, some morphological alterations were also detected in germlings grown in the presence of fungicides, consisting of multiple deformed hyphal tips, which appeared partly dead in hyphae challenged with fenhexamid. Altered morphology induced by $1 \mathrm{mgL}^{-1}$, or lower, benomyl treatments was detected in early studies on Neurospora crassa, Mycosphaerella musicola, Sclerotinia fructicola, Cercospora beticola, Verticillium theobromae, Botryosphaeria dothidea and Botrytis fabae, whose germ tubes appeared swollen, misshapen and frequently branched (Stover, 1969; Solel, 1970; Clemons and Sisler, 1971; Richmond and Pring, 1971; Penrose and Koffman, 1977; Li et al., 2002; Igeleke and Ayanru, 2007). A high number of short lateral branches showing retracted protoplasm and septa separating living from dead hyphal compartments was detected in PI and BAR mycelium at high glufosinate concentrations, suggesting that such morphological alterations, possibly related to the reduction of anastomosis ability, may occur following the inhibition of glutamine synthetase gene, as observed for appressorium differentiation in pathogenic fungi (Ahn, 2008). The important role played by amino acid biosynthesis during AMF development is confirmed by gene expression studies showing that glutamine synthetase genes were highly expressed during all stages of the fungal life cycle (Breuninger et al., 2004; Tisserant et al., 2012).

\section{Conclusions}

AMF may be considered as key bioindicators for soil quality, and further researches should assess functional and evolutionary consequences of the use of agricultural pesticides affecting AMF hyphal growth and fusion ability, including in the bioassays a wide range of AMF isolates and populations to exploit their large diversity. Although results obtained in our experimental system are not conclusive and should be validated for natural soil systems, they suggest that applica- tion of pesticides in agriculture may affect or not, depending on chemicals and dosages, AMF mycelial growth and functionality, even in disturbance-adapted species and that, in the worst scenario, they may pose serious threats to the maintenance of soil mycorrhizal potential and to AMF symbiotic performance in agroecosystems.

\section{Acknowledgements}

CBdN was supported by a post-doctoral scholarship from CAPES (Coordination for the Improvement of Higher Level Personnel).

\section{Funding sources}

The financial support of the University of Pisa (Fondi di Ateneo) and of CNR is gratefully acknowledged.

\section{Declaration of Competing Interest}

None.

\section{References}

Abass, M.H., 2017. In vitro antifungal activity of different plant hormones on the growth and toxicity of Nigrospora spp. on date palm (Phoenix dactylifera L.). Open Plant Sci. J 10-20.

Ahmad, I., Bisset, J., Malloch, D., 1995. Effect of phosphinothricin on nitrogen metabolism of Trichoderma species and its implications for their control of phytopathogenic fungi. Pest. Biochem. Physiol. 54, 49-59.

Ahn, I.P., 2008. Glufosinate ammonium-induced pathogen inhibition and defence responses culminate in disease protection in bar-transgenic rice. Plant Physiol. 146, 213-227.

Albrecht, M., Kortekamp, A., 2009. The in vitro effect of the herbicide Basta ${ }^{\circledR}$ (glufosinate ammonium) on potential fungal grapevine pathogens. Eur. J. Hort. Sci. 74, 112-117.

Angelard, C., Colard, A., Niculita-Hirzel, H., Croll, D., Sanders, I.R., 2010. Segregation in a mycorrhizal fungus alters rice growth and symbiosis-specific gene transcription. Curr. Biol. 20, 1216-1221.

Bartolome-Esteban, H., Schenck, N.C., 1994. Spore germination and hyphal growth of arbuscular mycorrhizal fungi in relation to soil aluminum saturation. Mycologia 86, 217-226.

Boatman, N., Paget, D., Hayman, D.S., Mosse, B., 1978. Effects of systemic fungicides on vesicular-arbuscular mycorrhizal infection and plant phosphate uptake. Trans. Br. Mycol. Soc. 70, 443-450.

Breuninger, M., Trujillo, C.G., Serrano, E., Fischer, R., Requena, N., 2004. Different nitrogen sources modulate activity but not expression of glutamine synthetase in arbuscular mycorrhizal fungi. Fungal Genet. Biol. 41, 542-552.

Brito, I., Goss, M.J., de Carvalho, M., Chatagnier, O., van Tuinen, D., 2012. Impact of tillage system on arbuscular mycorrhiza fungal communities in the soil under Mediterranean conditions. Soil Tillage Res. 121, 63-67.

Calonne, M., Fontaine, J., Debiane, D., Laruelle, F., Grandmougin-Ferjani, A., Lounès-Hadj Sahraoui, A., 2010. Propiconazole toxicity on the non-target organism, the arbuscular mycorrhizal fungus, Glomus irregulare. In: Carisse, O. (Ed.), Fungicides. InTech, Rijeka, pp. 325-346.

Calonne, M., Lounès-Hadj Sahraoui, A., Campagnac, E., Debiane, D., Laruelle, F., Grandmougin-Ferjani, A., Fontaine, J., 2012. Propiconazole inhibits the sterol 14a-demethylase in Glomus irregulare like in phytopathogenic fungi. Chemosphere 87, 376-383.

Campagnac, E., Fontaine, J., Lounès-Hadj Sahraoui, A., Laruelle, F., Durand, R., Grandmougin-Ferjani, A., 2008. Differential effects of fenpropimorph and fenhexamid, two sterol biosynthesis inhibitor fungicides, on arbuscular mycorrhizal development and sterol metabolism in carrot roots. Phytochemistry 69, 2912-2919.

Cardenas-Flores, A., Cranenbrouck, S., Draye, X., Guillet, A., Govaerts, B., Declerck, S., 2011. The sterol biosynthesis inhibitor molecule fenhexamid impacts the vegetative compatibility of Glomus clarum. Mycorrhiza 21, 443-449.

Carr, G.R., Hinkley, M.A., 1985. Germination and hyphal growth of Glomus caledonicum on water agar containing benomyl. Soil Biol. Biochem. 17, 313-316.

Castillo, C.G., Rubio, R., Rouanet, J.L., Borie, F., 2006. Early effects of tillage and crop rotation on arbuscular mycorrhizal fungal propagules in an Ultisol. Biol. Ferti. Soils 43, 83-92. https://doi.org/10.1007/s00374-005-0067-0.

Chiocchio, V., Venedikian, N., Martinez, A.E., Ana Menendez, A.M., Ocampo, J.A., Godeas, A., 2000. Effect of the fungicide benomyl on spore germination and hyphal length of the arbuscular mycorrhizal fungus Glomus mosseae. Int. Microbiol. 3, 173-175.

Clemons, G.P., Sisler, H.D., 1971. Localization of the site of action of a fungitoxic benomyl derivative. Pest. Biochem. Physiol. 1, 32-43.

Daniell, T.J., Husband, R., Fitter, A.H., Young, J.P.W., 2001. Molecular diversity of arbuscular mycorrhizal fungi colonising arable crops. FEMS Microbiol. Ecol. 36, 203-209.

Davidse, L.C., 1986. Benzimidazole fungicides: mechanism of action and biological impact. Annu. Rev. Phytopathol. 24, 43-65.

Debieu, D., Bach, J., Hugon, M., Malosse, C., Leroux, P., 2001. The hydroxyanilide fenhexamid, a new sterol biosynthesis inhibitor fungicide efficient against the plant 
pathogenic fungus Botryotinia fuckeliana (Botrytis cinerea). Pest manage. Sci. (formerly Pest. Sci.) 57, 1060-1067.

Declerck, S., Strullu, D.G., 2005. In vitro Culture of Mycorrhizas. vol. 4, Springer Science \& Business Media.

Dodd, J.C., Jeffries, P., 1989. Effect of fungicides on three vesicular-arbuscular mycorrhizal fungi associated with winter wheat (Triticum aestivum L.). Biol. Fertil. Soils 7, 120-128.

Ehinger, M., Croll, D., Koch, M.A., Sanders, I.R., 2012. Significant genetic and phenotypic changes arising from clonal growth of a single spore of an arbuscular mycorrhizal fungus over multiple generations. New Phytol. 196, 853-861.

Fomina, M., Ritz, K., Gadd, G., 2003. Nutritional influence on the ability of fungal mycelia to penetrate toxic metal-containing domains. Mycol. Res. 107, 861-871.

Fontaine, J., Grandmougin-Ferjani, A., Hartmann, M.A., Sancholle, M., 2001. Sterol biosynthesis by the arbuscular fungus Glomus intraradices. Lipids 63, 1357-1363.

Garcia-Romera, I., Ocampo, J.A., 1988. Effect of the herbicide MCPA on VA mycorrhizal infection and growth of Pisum sativum. Z Planzenenrnäl Bodenk 151, 225-228.

Giovannetti, M., Mosse, B., 1980. An evaluation of techniques for measuring vesicular-arbuscular mycorrhizal infection in roots. New Phytol. 84, 489-500.

Giovannetti, M., Sbrana, C., Avio, L., Citernesi, A.S., Logi, C., 1993. Differential hyphal morphogenesis in arbuscular mycorrhizal fungi during pre-infection stages. New Phytol. $125,587-594$.

Giovannetti, M., Turrini, A., Strani, P., Sbrana, C., Avio, L., Pietrangeli, B., 2006. Mycorrhizal fungi in ecotoxicological studies: soil impact of fungicides, insecticides and herbicides. Prev. Today 2, 47-61.

Giovannetti, M., Avio, L., Sbrana, C., 2015. Functional significance of anastomosis in arbuscular mycorrhizal networks. In: Mycorrhizal Networks. Springer, Dordrecht, pp. $41-67$.

Gisi, U., 1996. Synergistic interaction of fungicides in mixtures. Phytopathol. 86, 1273-1279.

Hale, K.A., Sanders, F.E., 1982. Effects of benomyl on vesicular arbuscular mycorrhizal infection of red clover (Trifolium pretense L.) and consequences for phosphorus inflow. J. Plant Nutr. 5, 1355-1367.

Hammersachlag, R.S., Sisler, H.D., 1973. Benomyl and methyl-2-benzimidazolecarbamate (MBC): biochemical cytological and chemical aspects of toxicity to Ustilago maydis and Saccharomyces cerevisiae. Pestic. Biochem. Physiol. 3, 42-54.

Helgason, T., Daniell, T.J., Husband, R., Fitter, A.H., Young, J.P.W., 1998. Ploughing up the wood-wide web?. Nature 394, 431.

Howard, R.J., Aist, J.R., 1980. Cytoplasmic microtubules and fungal morphogenesis: ultrastructural effects of methyl benzimidazole-2-ylcarbamate determined by freeze-substitution of hyphal tip cells. J. Cell Biol. 87, 55-64.

Igeleke, C.L., Ayanru, D.K.G., 2007. Evaluation of fungicides on growth and conidial germination of Verticillium theobromae isolated from plantain. J. Appl. Sci. 7, 531-535.

Ipsilantis, I., Samourelis, C., Karpouzas, D.G., 2012. The impact of biological pesticides on arbuscular mycorrhizal fungi. Soil Biol. Biochem. 45, 147-155.

ISO/TS 10832, 2009. Soil Quality - Effects of Pollutants on Mycorrhizal Fungi - Spore Germination Test

Jansa, J., Mozafar, A., Kuhn, G., Anken, T., Ruh, R., Sanders, I.R., Frossard, E., 2003. Soil tillage affects the community structure of mycorrhizal fungi in maize roots. Ecol. Appl. $13,1164-1176$

Johnson, N.C., Rowland, D.L., Corkidi, L., Egerton-Warburton, L.M., Allen, E.B., 2003. Nitrogen enrichment alters mycorrhizal allocation at five Mesic to semiarid grasslands. Ecology 84, 1895-1908.

Karpouzas, D.G., Papadopoulou, E., Ipsilantis, I., Friedel, I., Petric, I., Udikovic-Kolic, N., Djuric, S., Kandeler, E., Menkissoglu-Spiroudi, U., Martin-Laurent, F., 2014. Effects of nicosulfuron on the abundance and diversity of arbuscular mycorrhizal fungi used as indicators of pesticide soil microbial toxicity. Ecol. Indic. 39, 44-53.

Kling, M., Jakobsen, I., 1997. Direct application of carbendazim and propiconazole at field rates to the external mycelium of three arbuscular mycorrhizal fungi species: effect on $32 \mathrm{P}$ transport and succinate dehydrogenase activity. Mycorrhiza 7, 33-37.

Kortekamp, A., 2008. Knocked out with Basta ${ }^{\circledR}$ !-are herbicides effective against downy mildew of grapevine. J. Plant Dis. Prot. 107-112, Supplement · January 2008.

Kough, J.L., Gianinazzi-Pearson, V., Gianinazzi, S., 1987. Depressed metabolic activity of vesicular-arbuscular mycorrhizal fungi after fungicide applications. New Phytol. 106, 707-715.

Larsen, J., Thingstrup, I., Jakobsen, I., Rosendahl, S., 1996. Benomyl inhibits phosphorus transport but not fungal alkaline phosphatase activity in a Glomus - cucumber symbiosis. New Phytol. 132, 127-134.

Lenoir, I., Fontaine, J., Sahraoui, A.L.H., 2016. Arbuscular mycorrhizal fungal responses to abiotic stresses: a review. Phytochemistry $123,4-15$

Li, G.Q., Huang, H.C., Acharya, S.N., 2002. Sensitivity of Ulocladium atrum, Coniothyrium minitans, and Sclerotinia sclerotiorum to benomyl and vinclozolin. Can. J. Bot. 80, 892-898.

Mallmann, G.C., Sousa, J.P., Sundh, I., Pieper, S., Arena, M., da Cruz, S.P., Klauberg-Filho, O., 2018. Placing arbuscular mycorrhizal fungi on the risk assessment test battery of plant protection products (PPPs). Ecotoxicology 1-10.

Na Bhadalung, N., Suwanarit, A., Dell, B., Nopamornbodi, O., Thamchaipenet, A., Rungchuang, J., 2005. Effects of long-term NP-fertilization on abundance and diversity of arbuscular mycorrhizal fungi under a maize cropping system. Plant Soil 270, 371-382.

Öpik, M., Moora, M., Liira, J., Zobel, M., 2006. Composition of root-colonizing arbuscular mycorrhizal fungal communities in different ecosystems around the globe. J. Ecol. 94, 778-790.
Pawlowska, T.E., Charvat, I., 2004. Heavy-metal stress and developmental patterns of arbuscular mycorrhizal fungi. Appl. Environ. Microbiol. 70, 6643-6649.

Penrose, L.J., Koffman, W., 1977. Tolerance of Sclerotinia fructicola to benzimidazole fungicides and control of the fungus. J. Phytopathol. 88, 153-164.

Richmond, D.V., Phillips, A., 1975. The effect of benomyl and carbendazim on mitosis in hyphae of Botrytis cinerea Pers. ex Fr. and roots of Allium cepa L. Pest. Biochem. Physiol. 5, 367-379.

Richmond, D.V., Pring, R., 1971. The effect of benomyl on the fine structure of Botrytis fabae. Microbiology 66, 79-94.

Rose, M.T., Cavagnaro, T.R., Scanlan, C.A., Rose, T.J., Vancov, T., Kimber, S., Kennedy, I.R., Kookana, R.S., Van Zwieten, L., 2016. Impact of herbicides on soil biology and function. In: Sparks, D.L. (Ed.), Advances in Agronomy. vol. 136, Academic Press, pp. 133-220.

Sbrana, C., Turrini, A., Giovannetti, M., 2017. The crosstalk between plants and their arbuscular mycorrhizal symbionts: a mycocentric view. In: Seckbach, D. (Ed.), Biocommunication: Sign-mediated Interactions Between Cells and Organisms. pp. 285-308.

Sbrana, C., Strani, P., Pepe, A., de Novais, C.B., Giovannetti, M., 2018. Divergence of Funneliformis mosseae populations over 20 years of laboratory cultivation, as revealed by vegetative incompatibility and molecular analysis. Mycorrhiza 28, 329-341.

Schreiner, R.P., Bethlenfalvay, G.J., 1997. Mycorrhizae, biocides, and biocontrol 3. Effects of three different fungicides on developmental stages of three AM fungi. Biol. Fertil. Soils 24, 18-26.

Schweiger, P.F., Jakobsen, I., 1998. Dose-response relationships between four pesticides and phosphorus uptake by hyphae of arbuscular mycorrhizas. Soil Biol. Biochem. 30, 1415-1422.

Siqueira, J.O., Safir, G.R., Nair, M.G., 1991. VA-mycorrhizae and mycorrhiza stimulating isoflavonoid compounds reduce plant herbicide injury. Plant Soil 134, 233-242.

Smith, S.E., Read, D.J., 2008. Mycorrhizal Symbiosis. Academic Press and Elsevier, London.

Solel, Z., 1970. The systemic fungicidal effect of benzimidazole derivatives and thiophanate against Cercospora leaf spot of sugar beet. Phytopathol 60, 1186-1190.

Stover, R.H., 1969. The effect of benomyl on Mycosphaerella musicola. Plant Dis. Rep. 53, 830-833.

Sukarno, N., Smith, S.E., Scott, E.S., 1993. The effect of fungicides on vesicular-arbuscular mycorrhizal symbiosis I. The effects on vesicular-arbuscular mycorrhizal fungi and plant growth. New Phytol. 25, 139-147.

Sýkorová, Z., Ineichen, K., Wiemken, A., Redecker, D., 2007. The cultivation bias: different communities of arbuscular mycorrhizal fungi detected in roots from the field, from bait plants transplanted to the field, and from a greenhouse trap experiment. Mycorrhiza 18, 1-14.

Thingstrup, I., Rosendahl, S., 1994. Quantification of fungal activity in arbuscular mycorrhizal symbiosis by polyacrylamide gel electrophoresis and densitometry of malate dehydrogenase. Soil Biol. Biochem. 26, 1483-1489.

Tisserant, E., Kohler, A.C., Dozolme-Seddas, P., Balestrini, R., Benabdellah, K., Colard, A., Croll, D., Da Silva, C.M., Gomez, S.K., Koul, R., Ferrol, N., Fiorilli, V., Formey, D., Franken, P.H., Helber, N., Hijri, M., Lanfranco, L., Lindquist, E.A., Liu, Y., Malbreil, M., Morin, E., Poulain, J., Shapiro, H.J., van Tuinen, D., Waschke, A., Azcón-Aguilar, C., Bécard, G., Bonfante, P., Harrison, M.J., Küster, H., Lammers, P.J., Paszkowski, U., Requena, N., Rensing, S.A., Roux, C.P., Sanders, I.R., Shachar-Hill, Y., Tuskan, G.A., Young, J.P.W., Gianinazzi-Pearson, V., Martin, F.G.P., 2012. The transcriptome of the arbuscular mycorrhizal fungus Glomus intraradices (DAOM 197198) reveals functional tradeoffs in an obligate symbiont. New Phytol. 193, 755-769.

Toljander, J.F., Santos-González, J.C., Tehler, A., Finlay, R.D., 2008. Community analysis of arbuscular mycorrhizal fungi and bacteria in the maize mycorrhizosphere in a long-term fertilization trial. FEMS Microbiol. Ecol. 65, 323-338.

Trappe, J.M., Molina, R., Castellano, M., 1984. Reactions of mycorrhizal fungi and mycorrhiza formation to pesticides. Annu. Rev. Phytopathol. 22, 331-359.

Tubajika, K.M., Damann Jr, K.E., 2002. Glufosinate-ammonium reduces growth and aflatoxin B1 production by Aspergillus flavus. J. Food Protect. 65, 1483-1487.

Twanabasu, B.R., Smith, C.M., Stevens, K.J., Venables, B.J., Sears, W.C., 2013. Triclosan inhibits arbuscular mycorrhizal colonization in three wetland plants. Sci. Tot. Environ. $447,450-457$.

Uchimiya, H., Iwata, M., Nojiri, C., Samarajeewa, P.K., Takamatsu, S., Ooba, S., Anzai, H., Christensen, A.H., Quail, P.H., Toki, S., 1993. Bialaphos treatment of transgenic rice plants expressing a bar gene prevents infection by the sheath blight pathogen (Rhizoctonia solani). Biotechnology 11, 835-836.

Venedikian, N., Chiocchio, V., Martinez, A., Menendez, A., Godeas, A., Ocampo, J.A., 1999. Influence of the fungicides carbendazim and chlorothalonil on spore germination-arbuscular mycorrhizal colonization and growth of soybean plants [Glycine max (L.) Merr.]. Agrochimica 43, 105-109.

Zocco, D., Fontaine, J., Lozanova, E., Renard, L., Bivort, C., Durand, R., Grandmougin-Ferjani, A., Declerck, S., 2008. Effects of two sterol biosynthesis inhibitor fungicides (fenpropimorph and fenhexamid) on the development of an arbuscular mycorrhizal fungus. Mycol. Res. 112, 592-601.

Zocco, D., van Aarle, I.M., Oger, E., Lanfranco, L., Declerck, S., 2011. Fenpropimorph and fenhexamid impact phosphorus translocation by arbuscular mycorrhizal fungi. Mycorrhiza 21, 363-374. 